\title{
Ramp-Strike Risk Evaluation Making of Carrier-Based Aircraft
}

\author{
Hai-tao Jiang, Xiao-dong Su, Hui Li \\ School of Computer and Information Engineering \\ Harbin University of Commerce \\ hrbcu_lh@163.com
}

\begin{abstract}
To make "Ramp-Strike Risk" evaluation making accurately, this paper introduces a new wave-off risk assessment method based on neural network of carrier-based aircraft. On account of defining "Wave-Off Retain Clearance", the wave-off operation system with military power and vertical elevator is established as evaluation medium. The "Wave-Off Risk State Area" established by limited wave-off envelope can reduce network training burden, and the quantitative "Ramp-Strike Risk" function with flight state is presented through BP neural network finally. Simulation results show that the risk with flight states can be predicted by using new estimation method, moreover auxiliary rectification and earlywarning for landing is provided.
\end{abstract}

Keywords: Ramp-Strike Risk; Evaluation Making; Wave-Off Retain Clearance; Neural Network; Wave-Off Risk State Area

\section{Introduction}

On account of the significance of "Ramp-Strike Risk" problem and the gravity of evaluation circumstances, "Ramp-Strike Risk" evaluation making technology of carrier-based aircraft has the identical status with landing technique from a safety point of view. It is meaningful for analyzing risk emerging reason and making reasonable evaluation [1-2]. At present, the research of "Ramp-Strike Risk" evaluation making is based on initial flight state of aircraft and estimated qualitatively. This method is rough for analyzing approaching risk tendency by Landing Signal Officers (LSO) [3].

To make up the limitation of qualitative "Ramp-Strike Risk" evaluation technology, this paper presents a new risk evaluation making method based on neural network on account of the synthesize wave-off motion model. It computes landing risk under current flight status in real time. Simulation results show the predictive accuracy of the new way.

\section{Problem Formulation}

"Ramp-Strike Risk" where hook strikes ramp is the much important risk for carrier pilots universally acknowledged, and traditional wave-off risk research aims at this one. Because of fast velocity of aircraft and uncertainty of approaching status, it is difficult to evaluate the risk. Figure 1 shows the description of carrier-based aircraft "RampStrike Risk". 
Current Flight State ( $t_{1}$ moment)

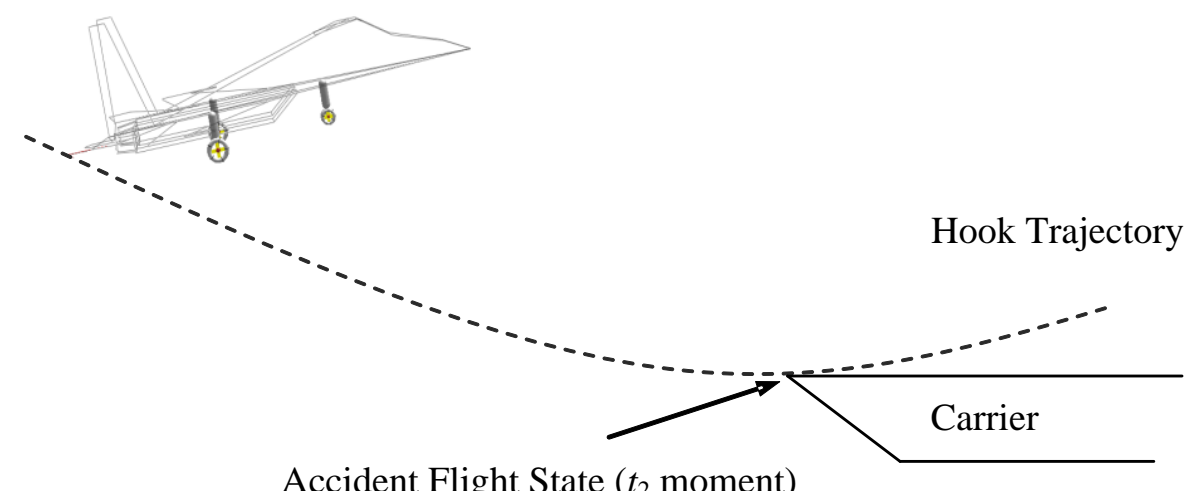

Figure 1 "Ramp-Strike Risk" of Carrier-Based Aircraft

Take into account of all of influencing factors, we will establish high-dimensional space probability function for the whole landing approach. "Ramp-Strike Risk" at $t_{1}$ moment is the actual accident occur probability at $t_{2}$ moment.

$$
R\left(p_{1}^{t_{1}}, p_{2}^{t_{1}}, \ldots, p_{n}^{t_{1}}\right)=f\left(p_{1}^{t_{2}}, p_{2}^{t_{2}}, \ldots, p_{n}^{t_{2}}\right) .
$$

Where $p_{i}^{t_{k}}(i=1,2, \ldots, n ; k=1,2)$ are flight states and environment states at $t_{k}$ moment.

Definition 1. "Wave-Off Retain Clearance (WRC)" is defined as the nearest clearance between hook of aircraft and ramp of carrier during wave-off process. "Ramp-Strike Risk" evaluates with WRC $S_{\mathrm{m} \text { in }}^{t_{k}}$ defined as [4-8]:

$$
R\left(p_{1}^{t_{k}}, p_{2}^{t_{k}}, \ldots, p_{n}^{t_{k}}\right)=g\left(S_{\min }^{t_{k}}\right) .
$$

To consider the generalization of system, this paper introduces BP neural network to impend over WRC $S_{\min }^{t_{k}}$, and finishes the conversion from flight state to $S_{\min }^{t_{k}}$.

\section{Wave-off Maneuvering Analysis}

\subsection{Wave-off operation}

Wave-off operation is the flight maneuvering when carrier-based aircraft makes sure land unsafely, it guarantees reasonable climbing rate and land safely. The force analysis of aircraft responding wave-off operation is shown as Figure 2. 


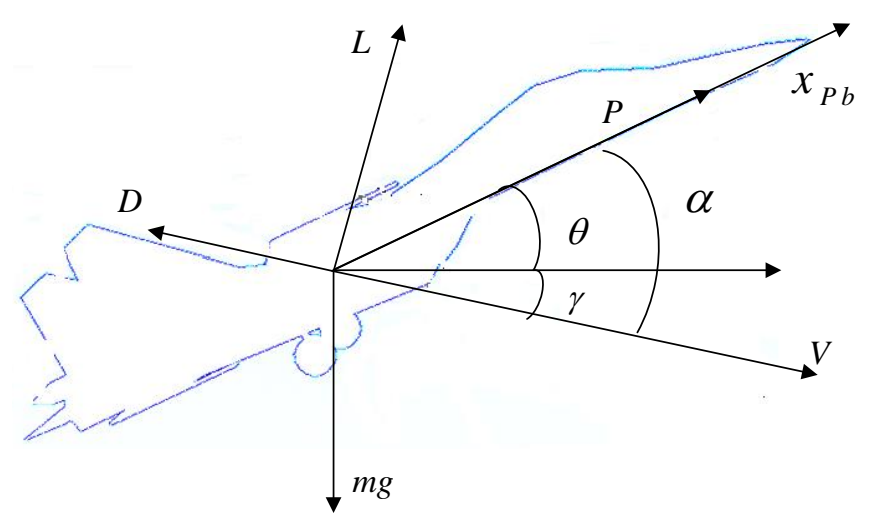

Figure 2 Force Analysis of Wave-off Operation

Through wave-off maneuvering process, the vertical motion relationship for carrierbased aircraft is:

$$
\left\{\begin{array}{c}
d V_{x g} / d t=(P \cos \theta+L \sin \gamma-D \cos \gamma) / m \\
d V_{z g} / d t=(G-P \sin \theta-L \cos \gamma-D \sin \gamma) / m \\
d x_{g} / d t=V \cos \gamma \\
d h / d t=V \sin \gamma
\end{array} .\right.
$$

Where lift force is:

$$
\begin{gathered}
L=C_{L} \rho V^{2} S / 2 . \\
C_{L}=C_{L 0}+C_{L \alpha} \alpha+C_{L \delta_{e}} \delta_{e} .
\end{gathered}
$$

Drag force is:

$$
\begin{gathered}
D=C_{D} \rho V^{2} S / 2 . \\
C_{D}=C_{D 0}+A_{L \alpha} \alpha^{2}+A_{\delta_{e}} \delta_{e}^{2} .
\end{gathered}
$$

\subsection{Wave-off system}

To choose military power and fuzzy elevator as wave-off maneuvering controller which can guarantee an appropriate angle of attack kept for reducing altitude loss [9], there are three limiting factors as follow.

Definition 2[10]. Airplane wave-off boundary criteria:

(1)Hook-to-ramp clearance shall be 10 feet.

(2)Pilot response shall be $0.7 \mathrm{~s}$.

(3)Wave-off technique is including military power with longitudinal control.

Through the rules above, the wave-off motion model which controlled by military thrust and elevator integrated control is established as Figure 3. We can describe the wave-off trajectory of carrier-based aircraft with function (8) as follow. 


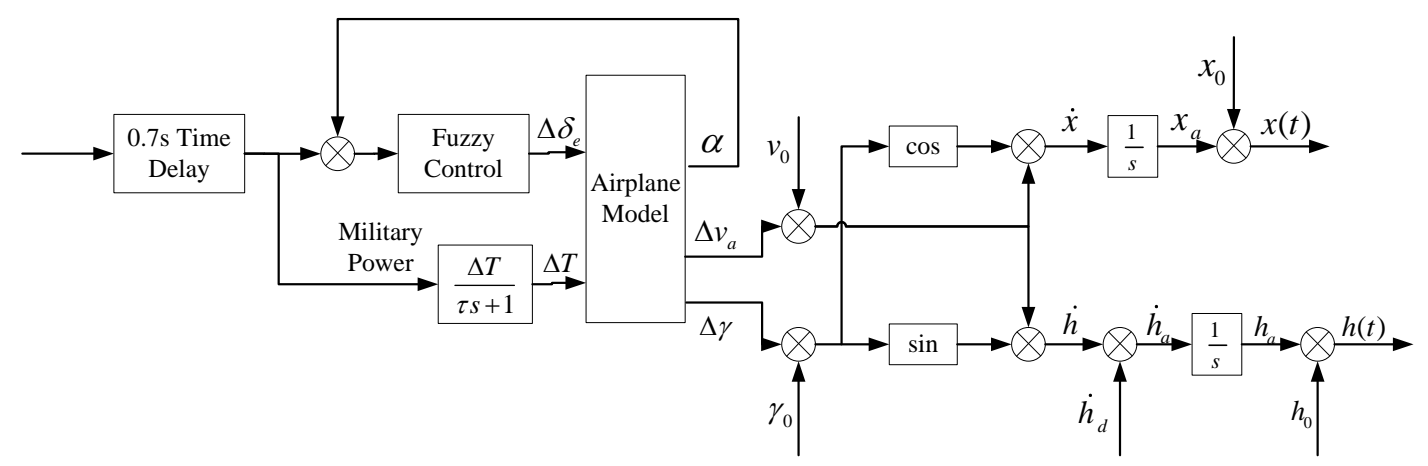

Figure 3 Military Thrust and Elevator Integrated Control Wave-off System

$$
\left\{\begin{array}{c}
x(t)=x_{0}+\int\left(v_{0}+\Delta v_{a}\right) \times \cos \left(\gamma_{0}+\Delta \gamma\right) \\
h(t)=h_{0}+\int\left[\left(v_{0}+\Delta v_{a}\right) \times \sin \left(\gamma_{0}+\Delta \gamma\right)+\dot{h}_{d}\right]
\end{array} .\right.
$$

Where $x_{0}, h_{0}, v_{0}, \gamma_{0}$ are the initial distance from ramp, height, closing speed and gliding angle of aircraft, and $\dot{h}_{d}$ is the interference sink rate.

To reduce mating difficulty of pilot conduct and optimal state, we choose the fuzzy control of manipulating elevator. Figure 4-6 present the attack angles, height deviations and wave-off boundaries with an interference sink rate $\dot{h}_{d}=0.5 \mathrm{~m} / \mathrm{s}$ and approach speed $v=69.96 \mathrm{~m} / \mathrm{s}$ for different control systems [10-12].

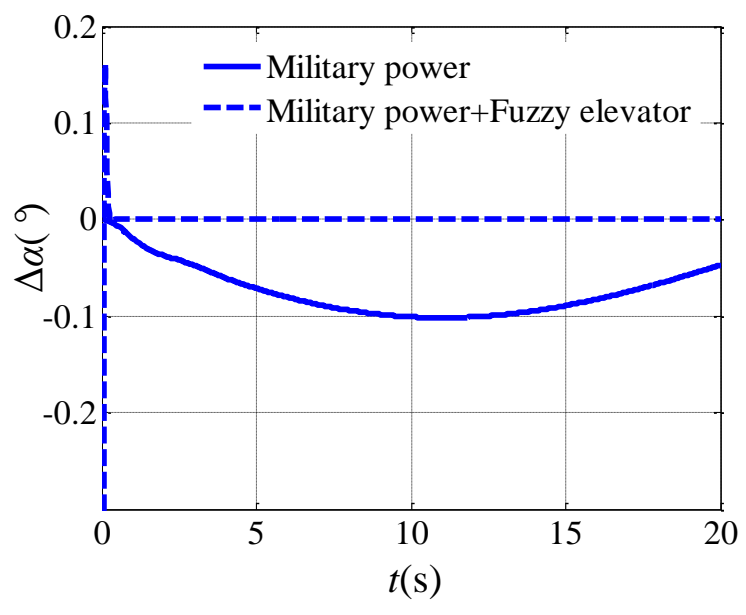

Figure 4 Response of Attack Angles 


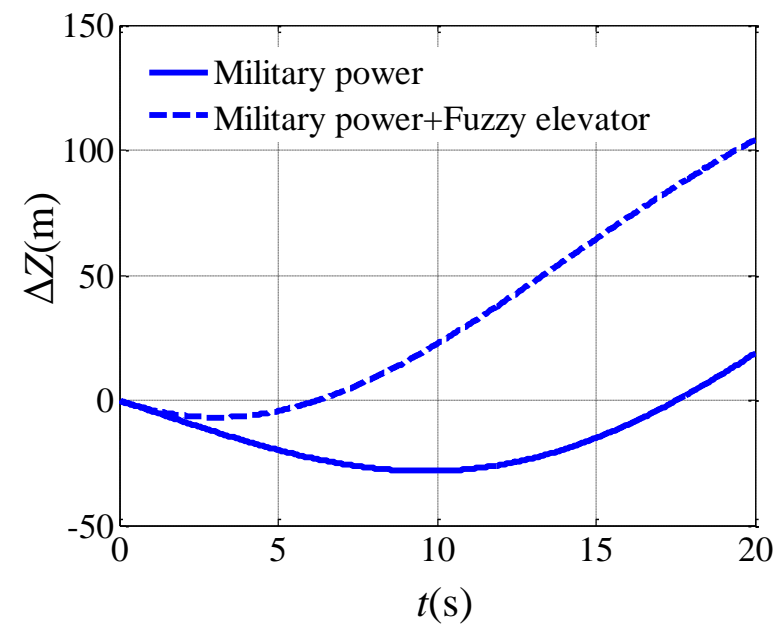

Figure 5 Response of Height Deviations

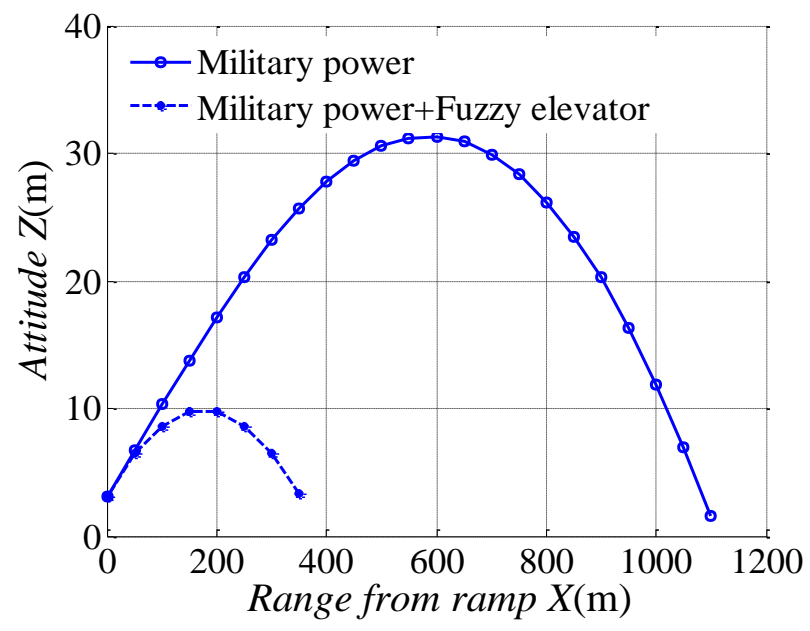

Figure 6 Wave-off Boundaries

Compared with only military power control technology, the integrated fuzzy control can decrease altitude loss (from $28.32 \mathrm{~m}$ to $6.86 \mathrm{~m}$ ), and has better control effect.

\section{4. "Ramp-Strike Risk" Evaluation Making Based on Neural Network}

\subsection{Wave-Off Risk State Area (WORSA)}

There are some affecting factors for the final hook-to-ramp clearance, such as: aircraft position $(x, z)$, closing speed $v$, interference sink rate $\dot{h}_{d}$ and ramp motion $h_{s}$. Figure 7 shows the dynamic curves of wave-off envelop with influencing factors above. 


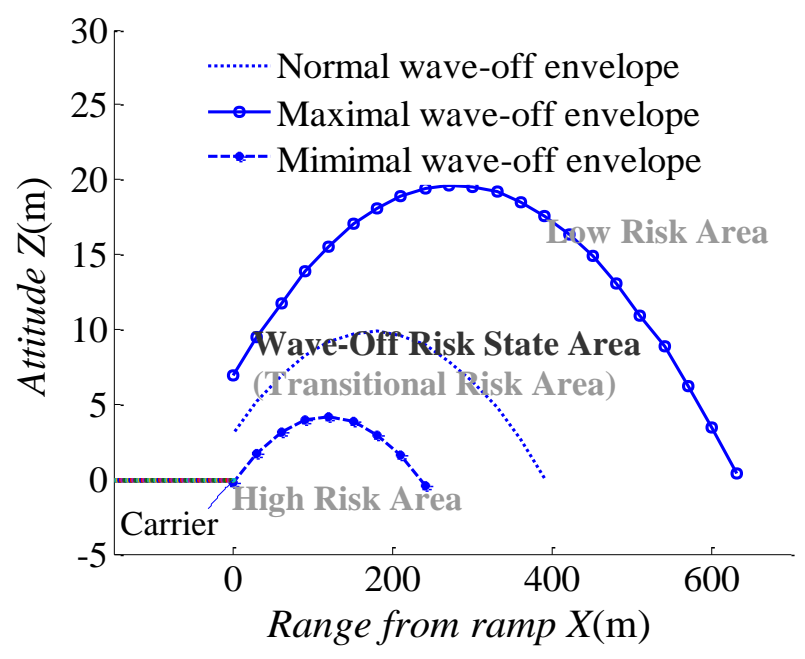

Figure 7 Wave-Off Risk State Area

"Maximal envelope" and "Minimal envelope" decollate the landing space into three parts: "Low Risk Area $\Gamma_{\text {Low Risk }}$ ", "High Risk Area $\Gamma_{\text {HighRisk }}$ "and "Transitional Risk Area $\Gamma_{\text {TransRisk }}$ ". It attaches the constants for $\Gamma_{\text {LowRisk }}$ and $\Gamma_{\text {HighRisk }}$ on account of less relationship related landing risk. But in $\Gamma_{\text {Transi isk }}$, there is a close relation between "Ramp-Strike Risk" and flight states of aircraft. As we know, $\Gamma_{\text {TransRisk }}$ is the "Wave-Off Risk State Area" in this paper. Function (9) can describe "Ramp-Strike Risk" under different areas.

$$
R\left(p_{1}^{t_{k}}, p_{2}^{t_{k}}, \ldots, p_{n}^{t_{k}}\right)=\left\{\begin{array}{cl}
0.1 & (x, z) \in \Gamma_{\text {Low Risk }} \\
g\left(S_{\mathrm{m} \text { in }}^{t_{k}}\right) & (x, z) \in \Gamma_{\text {TransRisk }} . \\
0.9 & (x, z) \in \Gamma_{\text {HighRisk }}
\end{array}\right.
$$

\subsection{BP neural network risk evaluation making}

4.2.1. Model training and testing: Figure 8 shows the BP network model with a 4-7-1 structure. After 600 model training, the network error shall be 0.00014. 102 groups of normalized test data is input to test for verifying generalization ability, as shown in Table 1. 


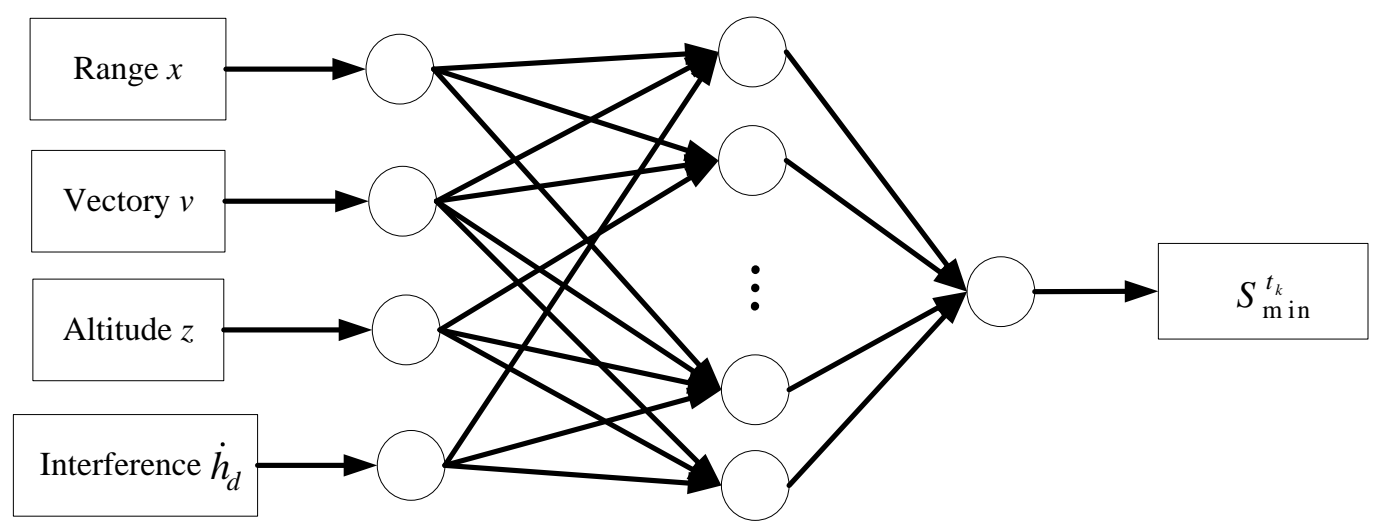

Input $\quad$ Input layer $\quad$ Hidden layer $\quad$ Output layer $\quad$ Output

Figure 8 BP Network Model

Table 1 BP Neural Network Testing

\begin{tabular}{|c|c|c|c|c|c|c|c|}
\hline Index & Input & $\begin{array}{c}\text { Excepted } \\
\text { output }\end{array}$ & $\begin{array}{l}\text { Actual } \\
\text { output }\end{array}$ & Index & Input & $\begin{array}{c}\text { Excepted } \\
\text { output }\end{array}$ & $\begin{array}{l}\text { Actual } \\
\text { output }\end{array}$ \\
\hline 1 & 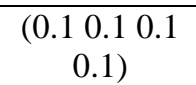 & 0.1 & 0.1096 & 15 & $\begin{array}{c}(0.50 .10 .58 \\
0.3)\end{array}$ & 0.1306 & 0.1620 \\
\hline 2 & $\begin{array}{c}\left(\begin{array}{ll}0.1 & 0.10 .74 \\
0.1)\end{array}\right.\end{array}$ & 0.1 & 0.1101 & 16 & $\begin{array}{c}(0.50 .30 .1 \\
0.9)\end{array}$ & 0.3249 & 0.3265 \\
\hline 3 & 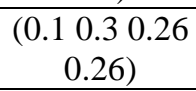 & 0.1878 & 0.1893 & 17 & $\begin{array}{c}(0.50 .30 .9 \\
0.26)\end{array}$ & 0.1212 & 0.1474 \\
\hline 4 & $\begin{array}{c}\left(\begin{array}{lll}0.1 & 0.3 & 0.9 \\
0.26)\end{array}\right.\end{array}$ & 0.1878 & 0.1903 & 18 & 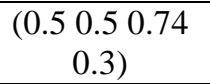 & 0.2144 & 0.236 \\
\hline 5 & $\begin{array}{c}\left(\begin{array}{ll}0.30 .10 .42 \\
0.3)\end{array}\right.\end{array}$ & 0.2218 & 0.1890 & 19 & $\begin{array}{c}\left(\begin{array}{l}0.50 .7 \\
0.42)\end{array}\right. \\
0.46\end{array}$ & 0.4333 & 0.4444 \\
\hline 6 & $\begin{array}{c}\left(\begin{array}{lll}0.3 & 0.1 & 0.9 \\
0.42)\end{array}\right. \\
\end{array}$ & 0.2419 & 0.1867 & 20 & $\begin{array}{c}(0.50 .70 .9 \\
0.74)\end{array}$ & 0.2741 & 0.2858 \\
\hline 7 & 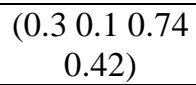 & 0.2231 & 0.1843 & $\cdots$ & $\cdots \cdots$ & $\cdots$ & $\ldots \ldots$ \\
\hline 8 & 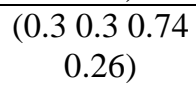 & 0.2099 & 0.2124 & 96 & $\begin{array}{c}\left(\begin{array}{ll}0.9 & 0.10 .1 \\
0.26)\end{array}\right.\end{array}$ & 0.6356 & 0.6605 \\
\hline 9 & $\begin{array}{c}\left(\begin{array}{lll}0.3 & 0.3 & 0.9 \\
0.74)\end{array}\right. \\
\end{array}$ & 0.1874 & 0.1882 & 97 & 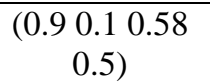 & 0.4078 & 0.3501 \\
\hline 10 & $\begin{array}{c}\left(\begin{array}{ll}0.30 .30 .58 \\
0.74)\end{array}\right. \\
\end{array}$ & 0.1412 & 0.1370 & 98 & $\begin{array}{c}(0.90 .30 .1 \\
0.9)\end{array}$ & 0.6315 & 0.6571 \\
\hline 11 & $\begin{array}{c}\left(\begin{array}{lll}0.3 & 0.5 & 0.1 \\
0.26)\end{array}\right.\end{array}$ & 0.1794 & 0.1585 & 99 & 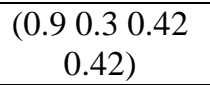 & 0.8846 & 0.8909 \\
\hline 12 & 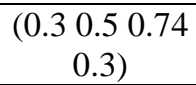 & 0.1411 & 0.1417 & 100 & 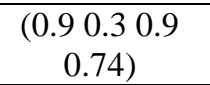 & 0.8372 & 0.8046 \\
\hline 13 & 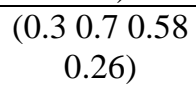 & 0.2354 & 0.2355 & 101 & $\begin{array}{c}(0.90 .740 .9 \\
0.74)\end{array}$ & 0.8745 & 0.8224 \\
\hline 14 & $\begin{array}{c}\left(\begin{array}{lll}0.5 & 0.1 & 0.1 \\
0.7\end{array}\right)\end{array}$ & 0.2375 & 0.2560 & 102 & $\begin{array}{c}\left(\begin{array}{lll}0.9 & 0.9 & 0.9 \\
0.26)\end{array}\right.\end{array}$ & 0.8812 & 0.9087 \\
\hline
\end{tabular}


4.2.2. Nonlinear transformation: After training network and inverse normalization (10), it is necessary to use nonlinear function (11) realizing the transformation from $S_{\mathrm{m} \text { in }}^{t_{k}}$ in $\Gamma_{\text {TransRisk }}$ to "Ramp-Strike Risk" $R\left(x_{k}, z_{k}, v_{k}, h_{d k}\right)$.

$$
\begin{aligned}
& S_{\min }^{t_{k}}=\frac{\left(v S_{\min }^{t_{k}}-0.1\right) \times\left(\left(S_{\min }^{t_{k}}\right)_{\max }-\left(S_{\min }^{t_{k}}\right)_{\min }\right)}{0.8}+\left(S_{\text {min }}^{t_{k}}\right)_{\min }=12.5 \times v S_{\text {min }}^{t_{k}}-1.25 . \\
& R\left(x_{k}, z_{k}, v_{k}, h_{d k}\right)=\left\{\begin{array}{cc}
0.1 & (x, z) \in \Gamma_{\text {Low } \text { isk }} \\
g\left(S_{\mathrm{min}}^{t_{k}}\right)=\frac{4}{\left.5+5 \exp \left(1.2 \times S_{\mathrm{min}}^{t_{k}}-5\right)\right)}+0.1 & (x, z) \in \Gamma_{\text {TransRisk }} . \\
0.9 & (x, z) \in \Gamma_{\text {HighRisk }}
\end{array}\right.
\end{aligned}
$$

\section{Simulation}

The 3-D surfaces of Wave-Off Retain Clearance $S_{\mathrm{min}}^{t_{k}}$ and "Ramp-Strike Risk" $R\left(x_{k}, z_{k}, v_{k}, h_{d k}\right)$ with $v=55 \mathrm{~m} / \mathrm{s}, \quad 67 \mathrm{~m} / \mathrm{s}$ and $85 \mathrm{~m} / \mathrm{s}$ are drawn as Figure 9 and Figure 10.

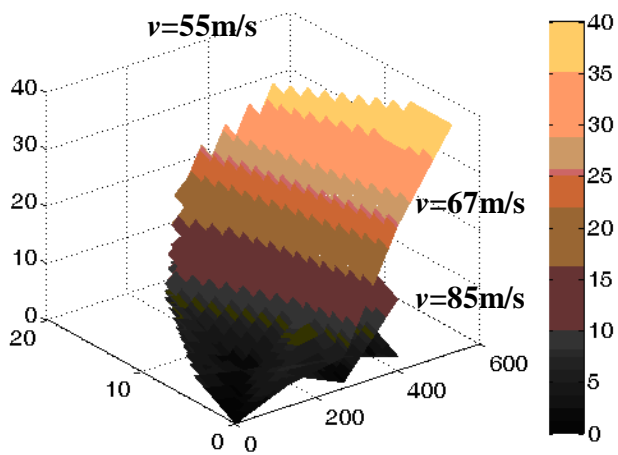

Figure 9 3D Surfaces of WRC

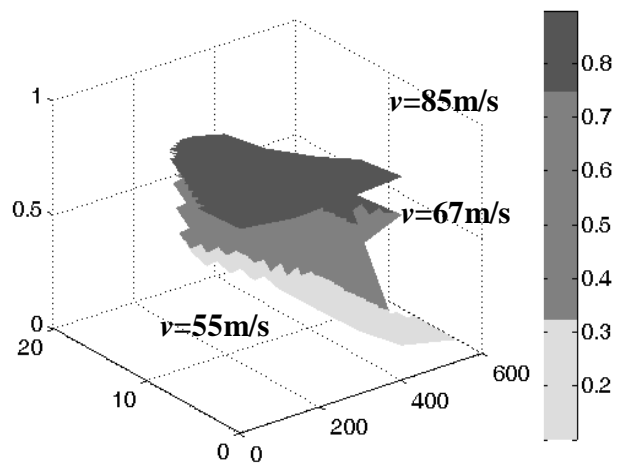

Figure 10 3D Surfaces of "Ramp-Strike Risk"

"Ramp-Strike Risk" increases with reduction of range and altitude. The law that the risk is gradually increasing with the increase of $v$ can be obtained by the comparison of risk surface with different velocities.

The 3-D surfaces of Wave-Off Retain Clearance $S_{\mathrm{min}}^{t_{k}}$ and "Ramp-Strike Risk" $R\left(x_{k}, z_{k}, v_{k}, h_{d k}\right)$ with $\dot{h}_{d}=-2 \mathrm{~m} / \mathrm{s}, \dot{h}_{d}=0 \mathrm{~m} / \mathrm{s}$ and $\dot{h}_{d}=2 \mathrm{~m} / \mathrm{s}$ are shown as Figure 11-12. 

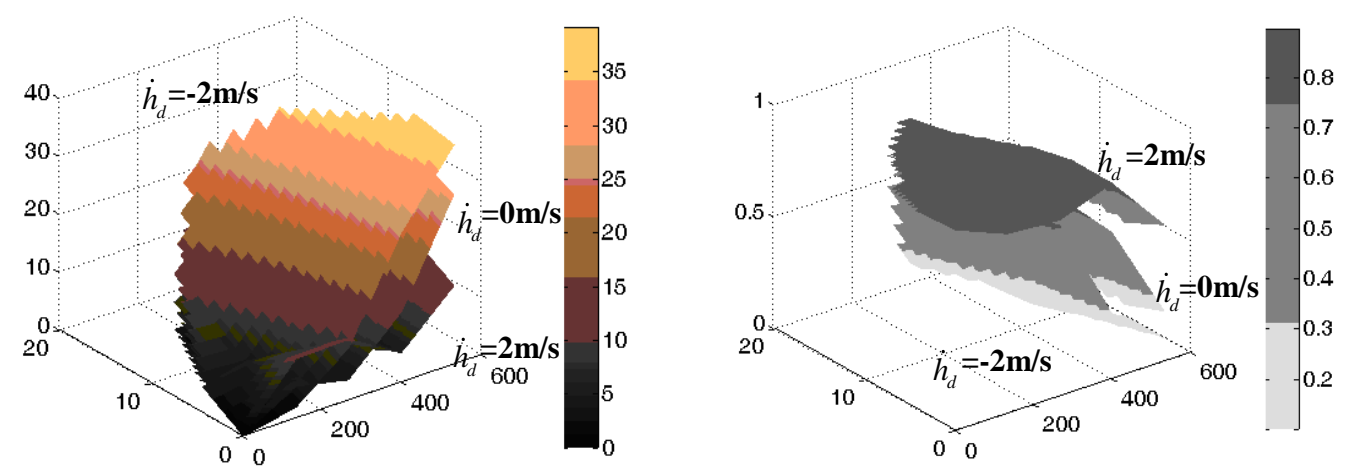

Figure 11 3D Surfaces of WRC

Figure 12 3D Surfaces of "Ramp-Strike Risk"

The risk is still increasing with range decreasing and attitude is proved again, and risk increases with the increase of $\dot{h}_{d}$ can be obtained.

\section{Conclusion}

This paper represents a new assessment way for "Ramp-Strike Risk" where WaveOff Retain Clearance as evaluation index. With the description of Wave-Off Risk State Area, a new evaluation method through neural network can be introduced. Through simulation, quantitative risk expression can implement under any flight states.

\section{ACKNOWLEDGEMENTS}

The author would like to thank the anonymous referees for their valuable suggestions. This work was supported by the Natural Science Foundation of Heilongjiang Province of China (Grant Nos. F201349) and Science and Technology Research Foundation of Heilongjiang Education Department (Grant Nos. 12531159)

\section{References}

[1] T. Rudowsky, S. Cook and M. Hynes, "Review of the Carrier Approach Criteria for Carrier-Based Aircraft", NAWCADPAX/TR-2002/71, (2002), Los Angeles.

[2] K. Robert and Heffley, "Outer-Loop Control Factor for Carrier Aircraft”, (1990), USA.

[3] "NATOPS Landing signal officer manual", (2001), US.

[4] R. B. Johnstone, "Development of the wave-off decision device and its relationship to the carrier approach problem", AIAA-68-846, American Inst of Aeronautics and Astronautics, Guidance, Control, and Flight Dynamics Conference. (1968) August 12-14, Calif, USA.

[5] Z. Qu, W. Wu and J. X. Qin, "Wave-Off Decision System Based on Small Disturbance Dynamics Model", Journal of Qingdao University (Natural Science Edition), vol. 23, no.4, (2010).

[6] J. Wang, W. Wu and L. Jia, "J. Study and Simulation Analysis on Wave-Off Capability of Carrier-Based Airplane”, Aircraft Design, vol. 30, no. 4, (2010).

[7] X. Zhang, K. Cui and W. Wu, "J. The Decision System for Wave-Off of Carrier-Based Aircraft. Journal of Naval Aeronautical and Astronautical University", vol. 24, no. 3, (2009).

[8] Z. Zhao and M. Liu, "J. The Development of Carrier-Based Aircraft Wave-Off Envelope Calculation Program", Flight Control\&Command Control, vol. 35, no. 6, (2010).

[9] R. A. Hess, "J. Simplified Approach for Modeling Pilot Pursuit Control Behaviour in Multi-Loop Flight Control Task", Institution of Mechanical Engineer, vol. 220, no. 2, (2006). 
[10] B. Wang, H. Gong and X. Wang, "J. Study on Intelligent Wave-Off Techniques Based on Fuzzy Control”, Journal of System Simulation, vol. 22, no. 1, (2010).

[11] H. Shen and Z. Gong, "J. Research on Wave-Off Decision and Control for Carrier Aircraft", Flight Dynamics, vol. 26, no. 5, (2008).

[12] B. Wang, H. Gong, X. Wang and Y. Yang, "J. Study on Intelligent Wave-Off Decision Techniques of Carrier Aircraft", Flignt Dynamics, vol. 28, no. 2, (2010).

[13] X. Min and T. Liu, "J. Application of BP Network Developed Using MATLAB Neural Network Toolbox", Computer Applications, vol. 21, no. 8, (2001).

[14] Y. Sun, W. Zeng and Y. Zhao, "J. Modeling of constitutive relationship of Ti600 alloy using BP Artificial Neutral Network”, Rare Metal Materials Engineering, vol. 40, no. 2, (2011).

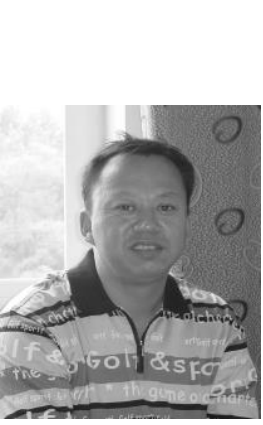

\section{Authors}

\section{Hai-tao Jiang}

$\mathrm{He}$ is an associate professor of Harbin University of Commerce. He received a M.E. degree in Software Engineering from Beijing University of Posts and Telecommunications, Beijing, China, 2010. His recent research interests are in intelligent control, digital signal processing and embedded technology.



\section{Xiao-dong Su}

$\mathrm{He}$ is a professor of Harbin University of Commerce and he is the member of council of the China Software Industry Association, vice president of Electronics Experiment Teaching Research Council of Universities in Heilongjiang, member of Heilongjiang Computer Society Education and Training Professional Committee. His recent research interests are in information detection and estimation, wireless communication theory and technology, management information systems.

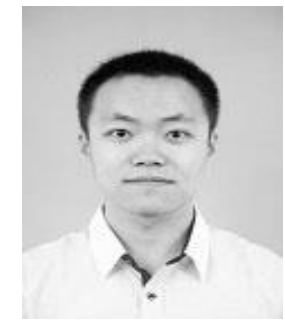

\section{Hui Li}

He received a D.E. degree in Control Theory and Control Engineering from Harbin Engineering University, Harbin, China, 2013. His recent research interests are in intelligent control, Multi-attribute decision making, fuzzy decisifon making. 